\title{
Compositional differences of Bojungikgi-tang decoctions using pressurized or non-pressurized extraction methods with variable extraction times
}

\author{
Jung-Hoon Kim, Chang-Seob Seo, Seong-Sil Kim, Hyeun-Kyoo Shin
}

Herbal Medicine Formulation Research Group, Korea Institute of Oriental Medicine, Daejeon, 305-811, Korea

\begin{abstract}
Objectives : In other to determine the optimal extraction conditions, the various Bojungikgi-tang (BJIGT) decoctions prepared by different pressure levels and different extraction times were compared and evaluated in terms of the extract yield and the total soluble solid content.

Methods : Decoctions were prepared by the pressure levels of 0 (non-pressurized) and $1 \mathrm{kgf} / \mathrm{cm}^{2}$ (pressurized) for 60, 120 and $180 \mathrm{~min}$. The extract yield and the total soluble solids content of decoctions were measured, and the amounts of the reference compounds in decoctions were investigated by the analysis using high performance liquid chromatography.

Results : The extract yield and the total soluble solid content were higher in decoctions extracted by the pressurized method than those from decoction with non-pressurized method. The patterns of yield and contents showed a proportional increase to the extraction time. In analysis of the linear regression for four reference compounds such as liquiritin, nodakenin, hesperidin, and glycyrrhizin, the good linearity with the correlation coefficient more than 0.9999 was observed. The highest contents for four reference compounds were observed at $180 \mathrm{~min}$ of both the pressurized method and the non-pressurized method.

Conclusions : This study suggests that the pressure in extraction method and the extraction time affect the compositional constituents in BJIGT decoctions. The extraction time of $180 \mathrm{~min}$ could be chosen in both pressurized and non-pressurized method as optimal extraction condition.
\end{abstract}

Key words : Bojungikgi-tang, extraction condition, extraction yield, total soluble solids content, reference compounds, regression analysis

\section{Introduction}

Decoction is an extraction method in herbal medicine that involves boiling herbs or plant materials to produce herbal formula. Extraction factors including temperature, time, or pressure can affect compositional constituents because decoction is produced by heating process in water. Hence, finding the optimum extraction conditions is critical for maximizing the therapeutic efficacy of herbal formula.

Bojungikgi-tang (BJIGT, Buzhongyiqi-tang in Chinese) is composed of eight herbal medicines, i.e., Astragali radix, Glycyrrhizae radix et rhizome, Ginseng radix,
Atractylodis rhizoma alba, Angelicae gigantis radix, Citri unshius pericarpium, Cimicifugae rhizome, and Bupleuri radix. In Korea, BJIGT is ranked ninth out of 56 formulas in terms of medicated days and medical expenses by Oriental Health Treatment and is also the second most frequently prescribed herbal formula in Korean medical clinics, which means it is the most frequently used herbal formula in a great many Korean medical institutes ${ }^{1,2)}$. BJIGT is officially registered in the latest edition of the Japanese pharmacopeia to control its safety and efficiency for meeting the general criteria of medicines ${ }^{3,4)}$.

Most studies have dealt with the relationship between

\footnotetext{
*Corresponding author : Hyeun-Kyoo Shin, Herbal Medicine Formulation Research Group, Korea Institute of Oriental Medicine, Daejeon, 305-811, Korea

- Tel : +82-42-868-9464 · Fax: +82-42-864-2120 · E-mail : hkshin@kiom.re.kr

\#Firts author : Jung-Hoon Kim, Herbal Medicine Formulation Research Group, Korea Institute of Oriental Medicine, Daejeon, 305-811, Korea

· Tel : +82-42-868- 9394 ·Fax：+82-42-864-2120 · E-mail : kmsct@kiom.re.kr

· 접수 : 2013년 6월 14일 · 수정 : 2013년 7월 10일 · 채택 : 2013년 7월 24일
} 
the extraction time and the amount of components in the decoction, such as the higher dissolution rates of baicalin and geniposide compared with the lower rates of alkaloid and wogonin with increasing extraction time, decreased levels of ingredients from Yinqiao-san with increased extraction time, and the enhanced extraction efficiency depending on the increased extraction time and volume of water ${ }^{5-7)}$. However, in-depth studies on the overall relationship between extraction method (pressurized or non-pressurized), extraction time, and thenceforth the compositional change of the decoction have rarely been reported in the previous literature.

In the present study, we prepared different types of ВЛGT decoctions by using pressurized or non-pressurized extraction methods for different extraction times (60, 120, and $180 \mathrm{~min}$ ) while the temperature was maintained at $100^{\circ} \mathrm{C}$. The extract yield and the total soluble solids content were determined, and the contents of reference compounds were analyzed using high performance liquid chromatography (HPLC) coupled with diode-array detection in each decoction. Regression analyses were performed using extraction yields, total soluble solids content, and the amount of reference compounds to find the relationship between the different types of extraction method and time, and to investigate the optimum decocting condition for BJIGT from the chemical standpoint.

\section{Materials and Methods}

\section{Reagents and herbal materials}

HPLC grade acetonitrile and water were purchased from J. T. Baker Inc. (Phillipsburg, NJ, USA) and GR grade acetic acid was obtained from Junsei (Tokyo, Japan). Standard compounds of liquiritin (98.0\%) and glycyrrhizin (99.0\%) were purchased from Wako Pure Chemical Industries Ltd (Osaka, Japan). Hesperidin $(\geq 98.0 \%)$ and nodakenin (99.0\%) were purchased from Chengdu Biopurity Phytochemicals Ltd (Chengdu, China) and NPC BioTech (Geumsan, Korea), respectively. The chemical structures of 4 standard compounds were shown in Fig. 1.

The herbal medicines comprising BJIGT were obtained from a local herbal market, Kwangmyoungdang Pharms (Ulsan, Korea), and the composition of the BJIGT herbal medicine was prepared according to the literature, as shown in Table $1^{8)}$. Voucher specimens (No. 201208) were deposited with the Basic Herbal Medicine Research Group in the Korea Institute of Oriental Medicine.
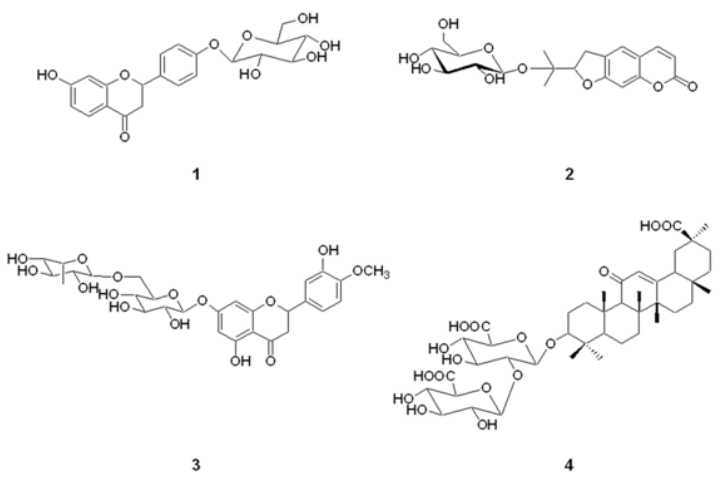

Fig. 1. Chemical structures of standard compounds in Bojungikgi-tang. (1) liquiritin, (2) nodakenin, (3) hesperidin, (4) glycyrrhizin.

\begin{tabular}{llc} 
Table 1: Composition of Medicinal Herbs in Bojungikgi-tang (BJIGT) \\
\hline \multicolumn{1}{c}{ Scientific nane } & \multicolumn{1}{c}{ Origin } & Amount (g) \\
\hline \hline Astragalus membranaceus (Fisch.) Bunge & Namwon, Jeonbuk, Korea & 5.625 \\
Glycyrrhiza uralensis Fisch. & China & 3.750 \\
Panax ginseng C.A. Meyer & Yeongju, Gyeongbuk, Korea & 3.750 \\
Atractylodes macrocephala Koidz. & China & 3.750 \\
Angelica gigas Nakai & Pyeongchang, Gangwon, Korea & 1.875 \\
Citrus unshiu (Swingle) Marcow. & Namjeju, Jeju, Korea & 1.875 \\
Cimicifuga heracleifolia Kom. & China & 1.125 \\
Bupleurum falcatum L. & Namwon, Jeonbuk, Korea & 1.125 \\
Net Amount (g) & & 22.875 \\
\hline
\end{tabular}

\section{Preparation of standard solutions}

Standard compounds were accurately weighed and dissolved in methanol to produce stock solutions at concentrations of $1 \mathrm{mg} / \mathrm{mL}$. Each stock solution containing a standard compound was diluted to make working solutions, which were used to construct calibration curves.

\section{Preparation of BJIGT decoctions}

The herbal medicines composing BJIGT were mixed and extracted at $100^{\circ} \mathrm{C}$ in water using a high-speed vacuum herb extractor (Cosmos 660, Kyungseo Machine, Incheon, Korea). A weight of $457.5 \mathrm{~g}$ corresponding to one formula set ('Je' in Korean), i.e., 20 times a single dose, was extracted to produce one set of decoctions. The extraction was carried out under pressurized (1.0 $\left.\mathrm{kgf} / \mathrm{cm}^{2}\right)$ or non-pressurized $\left(0 \mathrm{kgf} / \mathrm{cm}^{2}\right)$ methods for 60,120 , or $180 \mathrm{~min}$. The extraction water was regulated to make the final volumes of the decoctions around $3800 \mathrm{~mL}$. Each decoction was filtered through a $0.2 \mathrm{~mm}$ syringe filter (SmartPor ${ }^{\circledR}$; Woongki Science, Korea) prior to HPLC injection. 


\section{Measurements of the yield and total} soluble solids content

We concentrated $100 \mathrm{~mL}$ of each decoction by using a freeze-drier (IlshinBioBase, Dongducheon, Korea). To calculate the yield of decoctions, the weight of each freeze-dried decoction was converted to a percentage of the formula used for a single extraction. The total soluble solids content ( ${ }^{\circ}$ Brix) of each decoction was measured using a refractometer (Pal-a; ATAGO, Tokyo, Japan).

\section{Chromatographic conditions}

Chemical compounds were analysed using an HPLC system (LC-20A; Shimadzu, Japan) equipped with a solvent delivery unit (LC-20AT), autosampler (SIL-20AC), column oven (CTO-20A), photodiode array detector (SPD-M20A), and degasser (DGU-20A 3 ). The acquired data were processed using the LabSolutions software (Ver. 5.3; Shimadzu, Japan). Reference compounds were separated on a Gemini C18column(4.6mm' 250 $\mathrm{mm}, 5 \mathrm{~mm}$; Phenomenex, USA) maintained at $40^{\circ} \mathrm{C}$. The flow rate was $1.0 \mathrm{~mL} / \mathrm{min}$, and the injection volume was $10 \mu \mathrm{L}$. The mobile phase consisted of water containing $1.0 \%$ acetic acid (A) and acetonitrile containing $1.0 \%$ acetic acid (B), with the following elution gradient: 0-40 $\mathrm{min}, 5-70 \% \mathrm{~B}$; 40-45 min, 70$100 \% \mathrm{~B}$ holding for $5 \mathrm{~min}$. Each compound was quantified at its maximum wavelength in the UV spectrum (254, 280, and $335 \mathrm{~nm})$.

\section{Statistical analyses}

All experiments were performed at least three times. Two-tailed $t$-tests with Bonferroni corrections were conducted for the two-group and the multi-group comparisons in SYSTAT 10 (SPSS Inc., Chicago, IL, USA). Differences were considered significant at $P<$ $0.05, P<0.01$, or $\mathrm{P}<0.001$. Regression analysis was performed through extraction yields, total soluble solids content, and the amount of 4 reference compounds as perspective plot using open source software ' $R$ (ver. 2.15.2) .

\section{Results}

\section{Extraction yields and total soluble solids content of BJIGT decoctions}

As shown in Table 2, significant increases were observed in the yields of decoctions extracted using the pressurized method at $120 \mathrm{~min}$ and $180 \mathrm{~min}$ compared with 60 $\min$ (28.74 and 55.86\%, respectively) and there was also a significant increase at 180 min compared with 120 min (20.28\%). For non-pressurized extraction, although the yield increased with extraction time, the rate of increase was only significant at $120 \mathrm{~min}$ when compared with $60 \mathrm{~min}$ (32.94\%). Pressurized extraction represented significantly higher extraction yields (15.19\%) compared with non-pressurized extraction only at $180 \mathrm{~min}$.

There was also a significant increase in the total soluble solid content of decoctions extracted using the pressurized method at $120 \mathrm{~min}$ and $180 \mathrm{~min}$ compared with $60 \mathrm{~min}$ (36.89 and 48.42\%, respectively) while no significant increase was observed at $180 \mathrm{~min}$ compared with $120 \mathrm{~min}$. In the non-pressurized method, an increase in the total soluble solid contents was found only at 180 min compared with $60 \mathrm{~min}(28.41 \%)$. Pressurized extraction showed significantly higher extraction yields compared with non-pressurized extraction at 120 and $180 \mathrm{~min}$ (17.72 and $19.87 \%$, respectively).

Table 2: Extraction Yields and Total Soluble Solids Content of Decoctions Extracted Using Pressurized and Non-pressurized Methods

\begin{tabular}{|c|c|c|c|c|}
\hline \multirow{2}{*}{ Compound } & \multirow{2}{*}{ Method } & \multicolumn{3}{|c|}{ Extraction time $(\mathrm{min})$} \\
\hline & & 60 & 120 & 180 \\
\hline \multirow{2}{*}{ Extraction yield (\%) } & $\mathrm{PE}^{\mathrm{a}}$ & $19.34 \pm 0.18$ & $24.90 \pm 2.57^{*}$ & 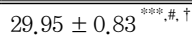 \\
\hline & $\mathrm{NPE}^{\mathrm{b}}$ & $18.61 \pm 1.56$ & $24.74 \pm 1.94^{\text {隶水 }}$ & $26.00 \pm 0.20^{\text {*** }}$ \\
\hline \multirow{2}{*}{$\begin{array}{l}\text { Total soluble solids } \\
\text { content ( } \mathrm{Bx})\end{array}$} & PE & $2.80 \pm 0.06^{\dagger}$ & $3.83 \pm 0.33^{*}, \dagger$ & 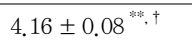 \\
\hline & NPE & $2.70 \pm 0.27$ & $3.26 \pm 0.17$ & $3.47 \pm 0.19^{*}$ \\
\hline
\end{tabular}

${ }^{a} \mathrm{PE}:$ pressurized extraction at $1.0 \mathrm{kgf} / \mathrm{cm}^{2}$.

${ }^{\mathrm{b}} \mathrm{NPE}$ : non-pressurized at $0 \mathrm{kgf} / \mathrm{cm}^{2}$.

Data expressed as average of triplicate measurements and values represented as 'Mean $\pm \mathrm{SD}$ '

Statistically significant at $P<0.05$ of values ${ }^{*}$ compared with the content at $60 \mathrm{~min},{ }^{\#}$ compared with the content at $120 \mathrm{~min},{ }^{\dagger}$ compared with the content at non-pressurized extraction.

\section{Linear equation, correlation coefficient $\left(r^{2}\right)$,}

\section{LOD and LOQ}

Good linearity was obtained with the correlation coefficient $\left(\mathrm{r}^{2}\right)$ for each compound ranging from 0.9999 to 1.0000 . The detection limit (LOD) and the quantification limit (LOQ) of the standard compounds were calculated based on concentrations having signal-to-noise ratios of 3 and 10, respectively. The range of the LOD was $0.02^{-} 0.11 \mathrm{mg} / \mathrm{mL}$, and that of the LOQ was $0.07-0.37 \mu \mathrm{g} / \mathrm{mL}$ (Table 3 ).

Table 3: Regression Equation, Correlation Coefficient $\left(r^{2}\right)$, Linear Range, LOD, and LOQ of Standard Compounds

\begin{tabular}{cccccc}
\hline Compound & Regression equation & $\mathrm{r}^{2}$ & $\begin{array}{c}\text { Linear range } \\
\left(\mathrm{mg} \mathrm{mL}^{-1}\right)\end{array}$ & $\begin{array}{c}\mathrm{LOD}^{\mathrm{a}} \\
\left(\mathrm{mg} \mathrm{mL}^{-1}\right)\end{array}$ & $\begin{array}{c}\mathrm{LOQ}^{\mathrm{b}} \\
\left(\mathrm{mg} \mathrm{mL}^{-1}\right)\end{array}$ \\
\hline \hline Liquiritin & $y=20514 \mathrm{x}-7654.6$ & 1.0000 & $3.91-250$ & 0.04 & 0.12 \\
Nodakenin & $y=37085 \mathrm{x}-13738$ & 0.9999 & $1.95-125$ & 0.02 & 0.07 \\
Hesperidin & $y=20889 \mathrm{x}-7846.3$ & 1.0000 & $3.91-250$ & 0.04 & 0.12 \\
Glycyrrhizin & $y=9010.1 \mathrm{x}-6021$ & 1.0000 & $3.91-250$ & 0.11 & 0.37 \\
\hline
\end{tabular}

${ }^{a} \mathrm{LOD}$ : limit of detection.

${ }^{\mathrm{b}} \mathrm{LOQ}$ : limit of quantification. 


\section{The contents of constituent compounds}

\section{in BJIGT decoctions}

The four reference compounds, namely liquiritin, nodakenin, hesperidin, and glycyrrhizin, which were known to be contained in the BJIGT decoction ${ }^{9,10)}$ were well separated on chromatograms by using the methods described above (Fig. 2).

At 60 and $120 \mathrm{~min}$, no significant difference was found in reference compound contents between pressurized and non-pressurized extraction except for nodakenin having higher contents in the pressurized method, while at $180 \mathrm{~min}$ there were significantly higher levels of the four compounds in decoctions produced using the non-pressurized method compared with the pressurized method (11.91-22.40\%). Significant increases were observed in the liquiritin concentrations at $180 \mathrm{~min}$ compared with $120 \mathrm{~min}$ (15.50\%) and a higher concentration was also found for hesperidin at $180 \mathrm{~min}$ compared with 60 and $120 \mathrm{~min}$ (13.77 and $11.70 \%)$ using the non-pressurized extraction method. In contrast to the results of yield and total soluble solids content, as shown in Table 4, pressurized and non-pressurized extraction methods showed no significant differences in the contents of reference compounds at both 60 and $120 \mathrm{~min}$, while at $180 \mathrm{~min}$ the four compounds were in higher concentrations in decoctions produced by non-pressurized extraction. Moreover, liquiritin and hesperidin were extracted with significantly higher concentration using the non-pressurized method at $180 \mathrm{~min}$.
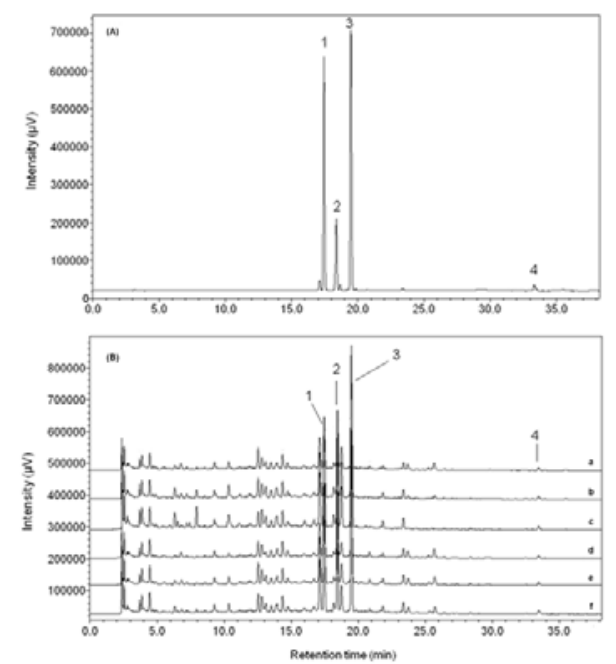

Fig. 2. Chromatograms of standard compound mixture (A) and Bojungikgi-tang decoctions produced by different extraction methods and times (B).

The pressurized method for (a) $60 \mathrm{~min}$, (b) $120 \mathrm{~min}$, and (c) 180 min, and the non-pressurized method for (d) $60 \mathrm{~min}$, (e) $120 \mathrm{~min}$ and $(\mathrm{f}) 180 \mathrm{~min}$ at a detection wavelength of $280 \mathrm{~nm}$. (1) liquiritin, (2) nodakenin, (3) hesperidin, and (4) glycyrrhizin.
Table 4: Content $(\mathrm{mg} / \mathrm{g})$ of Reference Compounds in Decoctions Extracted Using Pressurized and Non-pressurized Methods

\begin{tabular}{|c|c|c|c|c|}
\hline \multirow{2}{*}{ Compound } & \multirow{2}{*}{ Method } & \multicolumn{3}{|c|}{ Extraction time (min) } \\
\hline & & 60 & 120 & 180 \\
\hline \multirow{2}{*}{ Liquiritin } & $\overline{P E^{\mathrm{a}}}$ & $2.897 \pm 0.411$ & $3.357 \pm 0.264$ & $3.294 \pm 0.185$ \\
\hline & $\mathrm{NPE}^{\mathrm{b}}$ & $3.490 \pm 0.033$ & $3.414 \pm 0.219$ & $3.43 \pm 0.256^{*}, \dagger$ \\
\hline \multirow{2}{*}{ Nodakenin } & $\mathrm{PE}$ & $1.783 \pm 0.088^{\dagger}$ & $1.502 \pm 0.306$ & $1.447 \pm 0.100$ \\
\hline & NPE & $1.516 \pm 0.133$ & $1.586 \pm 0.141$ & $1.653 \pm 0.079^{\dagger}$ \\
\hline \multirow{2}{*}{ Hesperidin } & $\mathrm{PE}$ & $5.003 \pm 0.814$ & $4.888 \pm 0.454$ & $5.264 \pm 0.371$ \\
\hline & $\mathrm{NPE}$ & $5.220 \pm 0.217$ & $5.317 \pm 0.288$ & $5.939 \pm 0.072^{*, \#, \dagger}$ \\
\hline \multirow{2}{*}{ Glycyrrhizin } & $\mathrm{PE}$ & $4.077 \pm 0.512$ & $4.831 \pm 0.407$ & $4.264 \pm 0.310$ \\
\hline & NPE & $4.930 \pm 0.173$ & $4.642 \pm 0.508$ & $5.219 \pm 0.330^{\dagger}$ \\
\hline
\end{tabular}

${ }^{\mathrm{a}} \mathrm{PE}$ : pressurized extraction at $1.0 \mathrm{kgf} / \mathrm{cm}^{2}$.

${ }^{\mathrm{b}} \mathrm{NPE}$ : non-pressurized at $0 \mathrm{kgf} / \mathrm{cm}^{2}$.

Data expressed as average of triplicate measurements and values represented as 'Mean $\pm \mathrm{SD}$ '.

Statistically significant at $P<0.05$ of values ${ }^{*}$ compared with the content at $120 \mathrm{~min}$, " compared with the content at $60 \mathrm{~min}$, ${ }^{\dagger}$ compared with the content at non-pressurized extraction, ${ }^{\dagger}$ compared with the content at pressurized extraction.

\section{Regression analysis of BJIGT decoctions} with different extraction methods and extraction times

We performed regression analysis to find out the relationship between variables (yields, total soluble solids content, and the total content of 4 reference compounds) and extraction conditions (pressure and extraction time). Regression coefficients $\left(R^{2}\right)$ of 3 variables were $0.823,0.772$, and 0.376 , which higher $\mathrm{R}^{2}$ value close to 1 means better degree of correlation between the variables and extraction conditions ${ }^{11)}$. Higher $\mathrm{F}$-values were found in yields and total soluble solids content with $p$-values less than 0.001 while the total content of reference compounds showed lower $\mathrm{F}$-values with insignificant $p$-values (Table 5).

The perspective plot indicated that extraction yields and total soluble solids content were proportionally increased with extraction time and pressure, and the maximum values were observed at pressurized method $\left(1.0 \mathrm{kgf} / \mathrm{cm}^{2}\right)$ for $180 \mathrm{~min}$ (Fig. 3A and 3B). Total content of 4 reference compounds was proportional to extraction time while was inversely proportional to pressure, which maximum value was found at non-pressurized method $\left(0 \mathrm{kgf} / \mathrm{cm}^{2}\right)$ for $180 \mathrm{~min}$ (Fig. 3C).

Table 5: Regression Analysis of Extraction Conditions (Pressure and Extraction Time) on 3 Variables (Yields, Total Soluble Solids Content, and Total Content of 4 Reference Compounds)

\begin{tabular}{lccccc}
\hline \multicolumn{1}{c}{ Variable } & $\begin{array}{c}\text { Residual } \\
\text { standard error }\end{array}$ & $\begin{array}{c}\text { Degrees of } \\
\text { freedom }\end{array}$ & $\mathrm{R}^{2}$ & $\mathrm{~F}$-value & $p$-value \\
\hline \hline $\begin{array}{l}\text { Extraction yields } \\
\begin{array}{l}\text { Total soluble solids } \\
\text { content }\end{array}\end{array}$ & 1.77 & 15 & 0.823 & 40.66 & $8.761 \times 10^{-7}$ \\
$\begin{array}{l}\text { Total content of } \\
\text { reference compounds }\end{array}$ & 0.27 & 15 & 0.772 & 29.79 & $5.973 \times 10^{-} 6$ \\
\hline
\end{tabular}


(A)

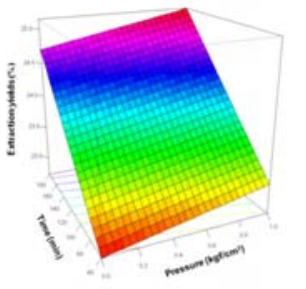

(B)

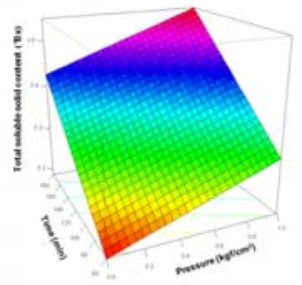

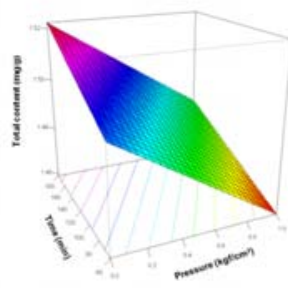

Fig. 3. Perspective plots of extraction yield, total soluble solids content, and total content of 4 reference compounds on extraction conditions (pressure and extraction time). (A) Extraction yield (\%), (B) total soluble solids content $\left({ }^{\circ} \mathrm{Bx}\right)$, and $(\mathrm{C})$ total content of 4 reference compounds $(\mathrm{mg} / \mathrm{g})$.

\section{Discussions}

In decoction, extraction factors including temperature, time, or pressure can affect compositional constituents because decoction is produced by heating herbal medicines in water. Hence, finding the optimum extraction conditions is critical for maximizing the therapeutic efficacy of herbal formula. In the present study, from the viewpoint of chemical characteristics for optimal extraction, pressure and extraction time were selected as influential factors while the temperature was maintained at $100^{\circ} \mathrm{C}$.

In our study, the yields, which could be interpreted as extraction efficiency, increased with longer extraction times using both pressurized and non-pressurized extraction methods, which agreed with previous literature reporting enhanced yields according to increasing extraction time ${ }^{12)}$. Pressurized extraction produced significantly higher yields than non-pressurized extraction at $180 \mathrm{~min}$, which indicates that pressure could also be an important factor affecting extraction efficiency, as reported in previous literature ${ }^{13-15)}$. The same result was observed in the total soluble solids content. The total soluble solids content consists of sugars, salts, proteins, and acids, and its value varied with the extraction solvent, the extraction time, and the temperature ${ }^{16,17)}$. The results show that the pressurized extraction method resulted in higher values of total soluble solids content than the non-pressurized method at 120 and $180 \mathrm{~min}$, which the values increased with longer extraction time as reported $^{17)}$. These results imply that higher pressure and longer extraction time increase the power of the solvent to break down the plant tissue cell wall, and, hence, compositional constituents or metabolites could be more effectively extracted from the inner cell, which is supported as an enhanced mass transfer rate to increase the cell permeability and secondary metabolite diffusion ${ }^{18)}$.

In contrast to the results of yield and total soluble solids content, the pressurized and non-pressurized extraction methods showed no significant differences in the contents of reference compounds at both 60 and $120 \mathrm{~min}$, while at $180 \mathrm{~min}$ the four compounds were in higher concentrations in decoctions produced by non-pressurized extraction. Moreover, liquiritin and hesperidin, of the four compounds, were extracted with significantly higher concentration using the non-pressurized method at $180 \mathrm{~min}$. In general, pressurized extraction forms higher amounts of phenolic compounds such as gallic acid, corilagin, ellagic acid and taxifolin-3-glucoside ${ }^{19,20)}$. However, in the present study, pressurized extraction did not show a higher extraction capacity for chemical compounds in overall extraction times; rather, the non-pressurized extraction produced increased contents of the four reference compounds with longer extraction time. These findings mean that the higher pressure conditions and accompanying high temperature might degrade or decompose the chemical compounds in the decoction over the extraction time, as shown in the pressurized decoction, although the differences are not significant.

The increased components contained as a result of the increased extraction yields and total soluble solids content, and the four reference compounds as bioactive compounds can be thought to be related to therapeutic effect of BJIGT. Because the amounts of components were easily affected by extraction conditions, finding their optimum conditions of extraction is much needed for the efficacy of BJIGT. Regression analysis was used to investigate the relationship between variables and extraction conditions, which tend to be more significant at greater $\mathrm{F}$-value and smaller $p$-value, indicating that model is significantly predictive under any combination of variables and extraction conditions, as shown in previous literatures ${ }^{11,12)}$. These results imply that increasing extraction time positively influences 3 variables, the extraction yields, total soluble solids, and total content of 4 reference compounds, in increasing manner, which values were highest at 180 min of extraction time. The pressure can enhance the extraction efficiency, however, it might have negative effect on the extraction of bioactive compounds.

\section{Conclusions}


In other to determine the optimal extraction conditions, the various Bojungikgi-tang (BJIGT) decoctions prepared by different pressure levels and different extraction times were compared.

1. The extract yield and the total soluble solid content were increased proportionally with the increase of pressure.

2. The levels of four reference compounds (liquiritin, nodakenin, hesperidin, and glycyrrhizin) were decreased with the additional pressure.

3. The decoctions by $180 \mathrm{~min}$ boiling showed the highest level of yields, total soluble solids content, and the levels of reference compounds, which were supported by perspective plot, as a result of regression analysis.

We conclude that the increased time in extraction process can enhance the extraction efficiency of compositional components of BJIGT even though the pressure can reduce the extraction of bioactive components.

\section{References}

1. Kim JD, Kang YG. National Health Insurance Statistical Yearbook. Seoul : National Health Insurance Corporation, Health Insurance Review \& Assessment Service. 2010 : 300-1.

2. Lee JT. Research on Intake of Chinese Medicine by Korean. Seoul : Korea Food and Drug Administration. 2006 : 94.

3. Tanaka K, Ina A, Ohta Y. Comparative study of chemical constituents of the traditional medicine hochuekkito by LC-MS with multivariate statistical analysis. J Trad Med. 2009 ; 26 : 179-86.

4. Society of Japanese Pharmacopeia. The Japanese Pharmacopeia. 16th ed. Tokyo : The Ministry of Health, Labour and Welfare Ministerial Notification No. 65. 2011 : 1583.

5. Lin J. Study on effective components of Huanglian Jiedu decoction in different decoction condition. China Medical Herald. 2010 ; 7: 50-1.

6. Lee YB, Kook YB, Choi SM. Study on the most effective Yinqiao San by the GC (Gas Chromatography). J Korean Medical Classics. 2006 ; 19: 202-6.

7. Sumino M, Saito Y, Ikegami F, Hirasaki Y, Namiki T. Extraction efficiency of Shosaikoto (Xiaochaihu tang) and investigation of the major constituents in the residual crude drugs. eCAM. 2012 : 1-7.

8. Heo J. Dongeuibogan. Seoul : Namsandang. 2007 :
434.

9. Ken T, Ina A, Ohta Y. Comparative study of chemical constituents of the traditional medicine hochuekkito by LC-MS with multivariate statistical analysis. J Trad Med. 2009 ; 26 : 179-86.

10. Weon JB, Ma JY, Yang HJ, Lee B, Yun BR, Ma CJ. Qualitative and quantitative analysis of nine major compounds in the Bozhougyiqi-Tang using a high-performance liquid chromatography coupled with a diode array detector and electrospray ionization mass spectrometer. Phcog Mag. 2013 ; 9(35) : 271-82.

11. Liu B, Guo F, Chang Y, Jiang H, Wang Q. Optimization of extraction of evodiamine and rutaecarpine from fruit of Evodia rutaecaroa using modified supercritical $\mathrm{CO}_{2}$. J Chromatogr A. $2010 ; 1217$ : 7833-9.

12. Zhong K, Wang Q. Optimization of ultrasonic extraction of polysaccharides from dried longan pulp using response surface methodology. Carbohydr Polym. $2010 ; 80: 19-25$.

13. Chen R, Meng F, Zhang S, Liu Z. Effects of ultrahigh pressure extraction conditions on yields and antioxidant activity of ginsenoside from ginseng. Sep Purif Technol. 2009 ; 66: 340-6.

14. Prasad KN, Yang B, Zhao M, Ruenroengklin N, Jiang Y. Application of ultrasonication or high-pressure extraction of flavonoids from Litchi fruit pericarp. J Food Process Eng. 2009 ; 32: 828-43.

15. Zulbadli N, Alwi H, Hamid KHK. Study on important factors affecting the extraction of momordica charantia using pressurized boiling system. ISBEIA. 2011 : 228-31.

16. Kim JH, Ahn SC, Choi SW, Hur NY, Kim BY, Baik MY. Changes in effective components of ginseng by puffing. J Korean Soc Appl Biol Chem. 2008 ; $51: 188-93$.

17. Kwak EJ. Development of brown colored rice tea with high GABA content. J Korean Soc Food Sci Nutr. $2010 ; 29$ : 1201-5.

18. Prasad KN, Yang E, Yi C, Zhao M, Jiang $Y$. Effects of high pressure extraction on the extraction yield, total phenolic content and antioxidant activity of longan fruit pericarp. Innov Food Sci Emerg Technol. 2009 ; 10: 155-9.

19. Prasad KN, Yang B, Shi J, Yu C, Zhao M, Xue S, Jiang Y. Enhanced antioxidant and antityrosinase activities of longan fruit pericarp by ultra-high-pressure-assisted extraction. J Pharm Biomed Anal. 2010 ; 51: 471-7.

20. Joo CG, Lee KH, Park C, Lee BC. Antioxidative activities and composition analysis of Pinus densiflora root by ultra high pressure extraction. $J$ Ind Eng Chem. $2011 ; 17$ : 712-6. 